OPEN ACCESS

Edited by:

Caicai Zhang,

Hong Kong Polytechnic University,

Hong Kong

Reviewed by:

Jing Zhao,

Capital Normal University, China

*Correspondence:

Wai Ting Siok

siok@hku.hk

Specialty section:

This article was submitted to

Language Sciences,

a section of the journal

Frontiers in Psychology

Received: 22 July 2020

Accepted: 18 August 2020

Published: 16 September 2020

Citation:

Siok WT and Luke KK (2020) Editorial: Reading in the Digital Age: The Impact of Using Digital Devices on Children's Reading, Writing and Thinking Skills. Front. Psychol. 11:586118. doi: 10.3389/fpsyg.2020.586118

\section{Editorial: Reading in the Digital Age: The Impact of Using Digital Devices on Children's Reading, Writing and Thinking Skills}

\author{
Wai Ting Siok ${ }^{1 *}$ and Kang Kwong Luke ${ }^{2}$ \\ ${ }^{1}$ Department of Linguistics, The University of Hong Kong, Pokfulam, Hong Kong, ${ }^{2}$ School of Social Sciences, Nanyang \\ Technological University, Singapore, Singapore
}

Keywords: reading and writing, digital devices, language and cognition, typewriting, literacy development

Editorial on the Research Topic

Reading in the Digital Age: The Impact of Using Digital Devices on Children's Reading, Writing and Thinking Skills

In the digital age, face-to-face communication is increasingly being supplemented, and in some cases even replaced, by computer-mediated communication. We interact less with each other directly but more through social media and other electronic platforms. New words and symbols are invented and syntax is modified to accommodate these needs, and these spread quickly through the virtual media. In schools and at home, children are being exposed to electronic-learning since a young age and knowledge acquisition is based on not just printed books but also electronic sources and internet contents. They handwrite less but type more, read less printed but more digital books, spell less but use more speech recognition engines to convert voice to text. Impaired readers may benefit from the audiobooks, and likewise dysgraphic children may write more by typewriting. How do the ever increasing exposure to electronic devices and the overwhelmingly rich information available on the internet affect children's reading, writing, and thinking skills? This Research Topic aims at understanding how the use of electronic devises has changed children's reading, writing, and thinking skills.

We are pleased to present four articles that contribute to this Research Topic. Two of the research papers suggest that careful use of digital tools may help children on their literacy skills. The study by Kloos et al. compares the effect of an online reading program with the usual classroom instruction on the reading fluency of elementary-school children. They report a positive effect of the former on the latter and explain how online programs can enrich individual experience by providing skilllevel appropriate lessons. In a different study, O'Brien et al. apply tablet-based literacy intervention to groups of bilingual children with special education needs. They argue that real-time data can be collected from the tablets during the intervention to track individual needs and thus tailor-made interventions can be provided to children in need.

But caution must be exercised when using these virtual techniques with very young children. Mayer et al. report that, although kindergarten children trained to handwrite letters and words using paper and pencil do not differ from those trained to write using keyboard in word reading and writing, the handwriting group have better performance in letter recognition and visuo-spatial skills. Importantly, children trained to handwrite using a stylus on a touchscreen perform less 
well in all literacy dimensions, possibly because the slippery surface of a touchscreen increases difficulty of motor control. Echoing the importance of handwriting on word recognition, Merritt et al. suggest that children should not be taught to handwrite following a strict stroke order but should be allowed to handwrite in a self-directed manner.

In summary, findings based on alphabetic languages seem to suggest that electronic-based learning, if used carefully and wisely, may generate positive learning outcomes particularly for children with special needs. This view needs to be more rigorously tested in future research using an extended sample covering a wider age range and including more languages. We look forward to more studies on this topic.

\section{AUTHOR CONTRIBUTIONS}

All authors listed have made a substantial, direct and intellectual contribution to the work, and approved it for publication.

Conflict of Interest: The authors declare that the research was conducted in the absence of any commercial or financial relationships that could be construed as a potential conflict of interest.

Copyright (c) 2020 Siok and Luke. This is an open-access article distributed under the terms of the Creative Commons Attribution License (CC BY). The use, distribution or reproduction in other forums is permitted, provided the original author(s) and the copyright owner(s) are credited and that the original publication in this journal is cited, in accordance with accepted academic practice. No use, distribution or reproduction is permitted which does not comply with these terms. 